\title{
As representações sociais do corpo para pessoas com deficiência física adquirida
}

\author{
Social representations of the body for people with physical disabilities
}

\section{Representaciones sociales del cuerpo para personas con discapacidad física}

\author{
Bruna Berri ${ }^{1}$, ORCID 0000-0003-4589-3909 \\ Andréa Barbará da Silva Bousfield ${ }^{2}$, ORCID 0000-0002-4333-4719 \\ Jean Paulo da Silva ${ }^{3}$, ORCID 0000-0001-5173-1856 \\ Andréia Isabel Giacomozzi ${ }^{4}$, ORCID 0000-0002-3172-5800
}

\section{Universidade Federal de Santa Catarina. Brasil}

\begin{abstract}
Resumo: O corpo é essencial na formação de impressões sobre alguém, ao se pensar em pessoas com deficiência física, o corpo torna-se o principal marcador da diferença. $\mathrm{Na}$ fundamentação teórica dessa pesquisa utilizou-se a Teoria das Representações Sociais e objetivou-se caracterizar as representações sociais do corpo para 12 homens e 12 mulheres com deficiência física adquirida. Como instrumentos utilizou-se entrevista semiestruturada e questionário sociodemográfico. Os dados foram analisados através de Classificação Hierárquica Descendente e análise descritiva. As representações sociais do corpo apresentaram dois eixos estruturais: saúde e estética. Não foram encontradas diferenças significativas nas representações sociais do corpo de homens e mulheres, contudo, alguns elementos vivenciais foram distintos, evidenciando manutenção de comportamento relacionado aos papeis de gênero. Mostra-se pertinente a criação de espaços públicos que se atentem à diversidade corporal e estratégias que estimulem a participação social e política das pessoas com deficiência.
\end{abstract}

Palavras-chave: representação social; corpo; deficiência física; pessoas com deficiência

Abstract: The body is essential in forming impressions on someone. When thinking about people with physical disabilities, the body becomes the main marker of difference. In the theoretical foundation of this research, the Theory of Social Representations was used. The objective was to characterize the social representations of the body for 12 men and 12 women with acquired physical disabilities. Semi-structured interviews and a sociodemographic questionnaire were used as instruments. The data were analyzed through Descending Hierarchical Classification and descriptive analysis. The social representations of the body presented two structural axes: health and aesthetics. No significant differences were found in the social representations of the body of men and women. However, some experiential elements were distinct, evidencing maintenance of behavior related to gender roles. It is pertinent to create public spaces that are attentive to the corporal diversity and strategies that stimulate the social and political participation of people with disabilities.

Key words: social representation; body; physical disability; people with disabilities 
Resumen: El cuerpo es esencial en la formación de impresiones sobre alguien, al pensar en personas con discapacidad física, el cuerpo se convierte en el principal marcador de la diferencia. En la fundamentación teórica se utilizó la Teoría de las Representaciones Sociales, se objetivó caracterizar las representaciones sociales del cuerpo para 12 hombres y 12 mujeres con deficiencia física adquirida. Como instrumentos se utilizó entrevista semiestructurada y cuestionario sociodemográfico, los datos fueron analizados a través de clasificación jerárquica descendente y análisis descriptivo. Las representaciones sociales del cuerpo presentaron dos ejes estructurales: salud y estética. No se encontraron diferencias significativas en las representaciones sociales del cuerpo de hombres y mujeres, sin embargo, algunos elementos fueron mantenimiento existencial distinto del comportamiento relacionado con papel de género. Se muestra pertinente la creación de espacios públicos que se atenten a la diversidad corporal y estrategias que estimulen la participación social y política de las personas con discapacidad.

Palabras clave: representación social; cuerpo; medios de comunicación; discapacidad; personas con discapacidad

Recebido: 10/06/2019

Aceito: $18 / 09 / 2020$

\section{Como citar:}

Berri, B., Bousfield, A.B.S., Silva J.P., \& Giacomozzi A.I. (2020). As representações sociais do corpo para pessoas com deficiência física adquirida. Ciencias Psicológicas, 14(2), e-2322. doi: https://doi.org/10.22235/cp.v14i2.2322

Correspondência: Bruna Berri, e-mail: brunaberri@hotmail.com. Andréa Barbará da Silva Bousfield, e-mail: andreabs@gmail.com. Jean Pauloda Silva, e-mail: jeanps.silva@gmail.com. Andréia Isabel Giacomozzi, e-mial: agiacomozzi@hotmail.com. Laboratório de Psicologia Social da Comunicação e Cognição, UFSC - CFH Departamento de Psicologia - Campus Universitário Trindade. Bloco E - 5o andar CEP:88.040-900 - Florianópolis $-S C$

São várias as conceituações relacionadas ao corpo que abrangem desde seus aspectos físicos até aspectos imaginários. Esse estudo utiliza-se da definição proposta por Andrieu (2006) que define o corpo enquanto um programa genético que se desenvolve a partir de uma maior ou menor plasticidade biocultural. No Brasil, há cerca de 45 milhões de brasileiros com algum grau de deficiência (IBGE, 2011), representando 23,9\% do total da população, entre esses, 13 milhões apresentam impedimentos graves. São consideradas pessoas com deficiência aquelas que apresentam, a longo prazo, impedimentos de natureza física, intelectual ou sensorial que quando em interação com barreiras diversas interrompem a participação plena na sociedade quando comparado as condições das demais pessoas (I Convenção sobre os Direitos das Pessoas com Deficiência, 2007). Dados do IBGE (2011) mostram que 1,3\% da população brasileira possui algum tipo de deficiência física/motora, destes, quase a metade $(46,8 \%)$ em grau intenso ou muito intenso de limitações.

Quando se trata de deficiência física, o corpo é o principal marcador da diferença, contudo, ressalta-se que a ideia de um corpo perfeito e completo é utópica uma vez que a sociedade contemporânea estabelece cada vez mais padrões restritos e idealizados (Meurer \& Gesser, 2008). Padrões de beleza inalcançáveis contribuem para a discriminação de pessoas com deficiência física devido aos estereótipos que guiam as relações da população com o corpo "diferente". Assim, a aparência física, representada no corpo como objeto social, se caracteriza como um contexto 
privilegiado para estudo da interação entre aspectos individuais e coletivos, uma vez que emerge como mediador do lugar social e das relações sociais estebelecidas pelas pessoas (Jodelet, 2017; Jodelet et al., 1982) se relacionando aos processos de categorização social (Justo, Camargo \& Bousfield, 2020).

A Teoria das Representações Sociais (TRS), elaborada por Moscovici (1961/2012), traz as representações sociais como formas de conhecimento do mundo socialmente partilhadas, as quais permitem dar sentido a fatos novos ou desconhecidos, contribuindo para processos de formação das comunicações sociais. Com um caráter dinâmico, as representações sociais são uma rede de crenças, metáforas, comportamentos e imagens que se articulam de modo fluído (Camargo et al., 2011), associando-se a uma noção que conforme Arruda (2015) remete ao imaginário social.

Iniciado pelo estudo de Jodelet $(1984,1986,1994)$, pesquisadores vêm se dedicando ao conhecimento das representações sociais do corpo, relacionando-as com aspectos como a imagem, envelhecimento, estética, saúde, entre outros, contudo, estudos que relacionam as representações sociais do corpo para pessoas com deficiência física são dificilmente encontrados (Agmon, Sa'ar, \& Araten-Bergman, 2016; Jones et al., 2015).

Nesse contexto, aspectos de representações sociais relativos ao corpo possuem diferenças significativas entre homens e mulheres, de forma geral mulheres apresentam menor autoestima, menor satisfação corporal e maior pressão estética por parte social e midiática (Camargo, Justo, \& Aguiar, 2008; Castilho, 2001; Furtado, 2009). Entender as diferenças entre os gêneros contribuirá para a compreensão das variáveis que influenciam a formação de representações sociais no contexto do corpo como objeto social.

Especificamente sobre como pessoas com deficiência são representadas de modo geral, enquanto homens com deficiência são vistos como impotentes e incapazes de amar, mulheres são vistas como passivas, vulneráveis e dependentes - uma figura frágil e inocente que deve ser resgatada por um homem "capaz" (Barnes \& Mercer, 2001). Entende-se que, devido a esse contexto social, homens e mulheres com deficiência experenciam o corpo de formas diferentes.

Segundo Mello e Nuernberg (2012) o fenômeno da deficiência física não se encerra no corpo por si mesmo, mas na produção de uma cultura e sociedade que determina certas variações corporais como inferiores, incompletas, ou ainda passíveis de reparação quando localizadas em relação à corponormatividade.

Mello, Nuernberg e Block (2014) referem-se ao surgimento do Modelo Social da Deficiência como uma contraposição ao Modelo Médico da Deficiência, que se norteia pela ideia de cura ou medicalização do corpo deficiente. O Modelo Social implica em visualizar a deficiência para além do corpo: como a interação dessa pessoa com o seu entorno social e ambiental. Dessa forma, o "problema" da deficiência passa a ser estrutural e social uma vez que é a sociedade que não abarca a diversidade corporal impondo às pessoas diversas barreiras.

A partir dos referenciais teóricos apresentados, esse estudo teve como objetivo caracterizar as representações sociais do corpo para homens e mulheres com deficiência física adquirida.

\section{Método}

A presente pesquisa é um estudo de observação indireta com abordagem qualitativa, de natureza exploratória, descritiva e comparativa, com corte transversal (Gil, 2008; Sampieri, Collado, \& Lúcio, 2013). Foram utilizados estudos de caso com o objetivo de investigar em profundidade os objetos da pesquisa (Yin, 2001). Participaram 24 pessoas com deficiência física adquirida na faixa etária de jovens e adultos ${ }^{1}$, pareados por sexo, residentes na região da Grande

\footnotetext{
${ }^{1}$ Uma vez que grande parte das pessoas com deficiência física adquirem a deficiência através da perda de funcionalidade corporal em decorrência da velhice, esse estudo abordou apenas a faixa etária de jovens e adultos (entre 18 e 59 anos), evitando aspectos representacionais relativos ao processo de envelhecimento na investigação das questões corporais da deficiência física.
} 
Florianópolis. A escolha do número de participantes seguiu o critério de saturação dos dados (Ghiglione \& Matalon, 1993).

O instrumento de coletas de dados foi composto por um roteiro de entrevista semidiretiva para os conteúdos relacionados ao corpo e à deficiência física e um questionário sociodemográfico. Os participantes foram acessados a partir da técnica de amostragem por bola de neve (Flick, 2009). O primeiro participante foi acessado por conveniência, partindo da rede de relações da pesquisadora.

As informações obtidas nas entrevistas relacionadas ao corpo e deficiência física foram organizadas em um só corpus textual e analisadas por meio de Classificação Hierárquica Descendente (CHD) com o software IRaMuTeQ (Interface de $R$ pour les Analyses Multidimensionnelles de Textes et de Questionnariores). A CHD tem como objetivo criar classes de segmentos de textos contendo, ao mesmo tempo, vocabulários semelhantes entre si, mas diferentes dos segmentos de textos de outras classes (Camargo \& Justo, 2013). No campo da psicologia social, particularmente nos estudos de representações sociais, tendo em vista a importância que se atribui às manifestações linguísticas, as classes geradas pelo software podem indicar representações sociais ou aspectos dela (Veloz, Nascimento-Schulze, \& Camargo, 1999).

Para comparar as representações dos participantes homens e mulheres realizou-se uma Análise de Especificidades também com o software IRaMuTeQ. Este recurso, também conhecido como Análise de Contrastes, permite a associação dos segmentos de textos com as variáveis de escolha do pesquisador (Camargo \& Justo, 2013), nesta pesquisa, a variável sexo. Além disso, a fim de caracterizar a amostra, foi realizada análise estatística descritiva (média, desvio-padrão e frequência) com o emprego do software Statistical Package for the Social Science - SPSS, versão 17.0.

O projeto número 2.008.560 obteve parecer favorável do Comitê de Ética em Pesquisa com Seres Humanos da UFSC. Ainda, a pesquisa respeita o sigilo dos participantes e a participação desses foi voluntária, mediante assinatura do Termo de Consentimento Livre e Esclarecido TCLE.

\section{Resultados}

Participaram 12 homens e 12 mulheres com idade entre 20 e 52 anos $(M=36$ anos e 3 meses; $D P=9$ anos e 7 meses) com deficiência física adquirida, sendo a maior parte com paraplegia (15), cinco com tetraplegia, três com amputações de um membro inferior e um com paresia. A média de tempo de aquisição da deficiência foi de 12 anos e 1 mês ( $D P=9$ anos).

Além das perguntas abertas relacionadas ao corpo, objeto principal do estudo, os participantes foram questionados sobre a deficiência física, objetivando assim o entendimento de como esses fenômenos se articulam. As 24 entrevistas foram transcritas e organizadas em um único corpus textual bitemático corpo e deficiência, compondo o material de análise. Cada entrevista foi identificada por uma linha de comando com as variáveis: sexo e tipo de deficiência física. Ao submeter o corpus à CHD, o material dividiu-se em 24 textos com total de 3013 segmentos de texto, desses $90,54 \%$ foram retidos na análise.

O corpus foi divido em cinco classes de conteúdos. Primeiramente, a CHD dividiu o corpus em dois subcorpora, diferenciando as Classes 1 e 4 das demais classes. Em seguida, o segundo subcorpora foi particionado, separando a Classe 5 das Classes 3,1 e 2 que, por sua vez, também foram separadas em duas partes, originando a Classe 3 e, por fim, as Classes 1 e 2 . Observa-se na Figura 1 as classes originadas pela CHD e nomeadas manualmente. 


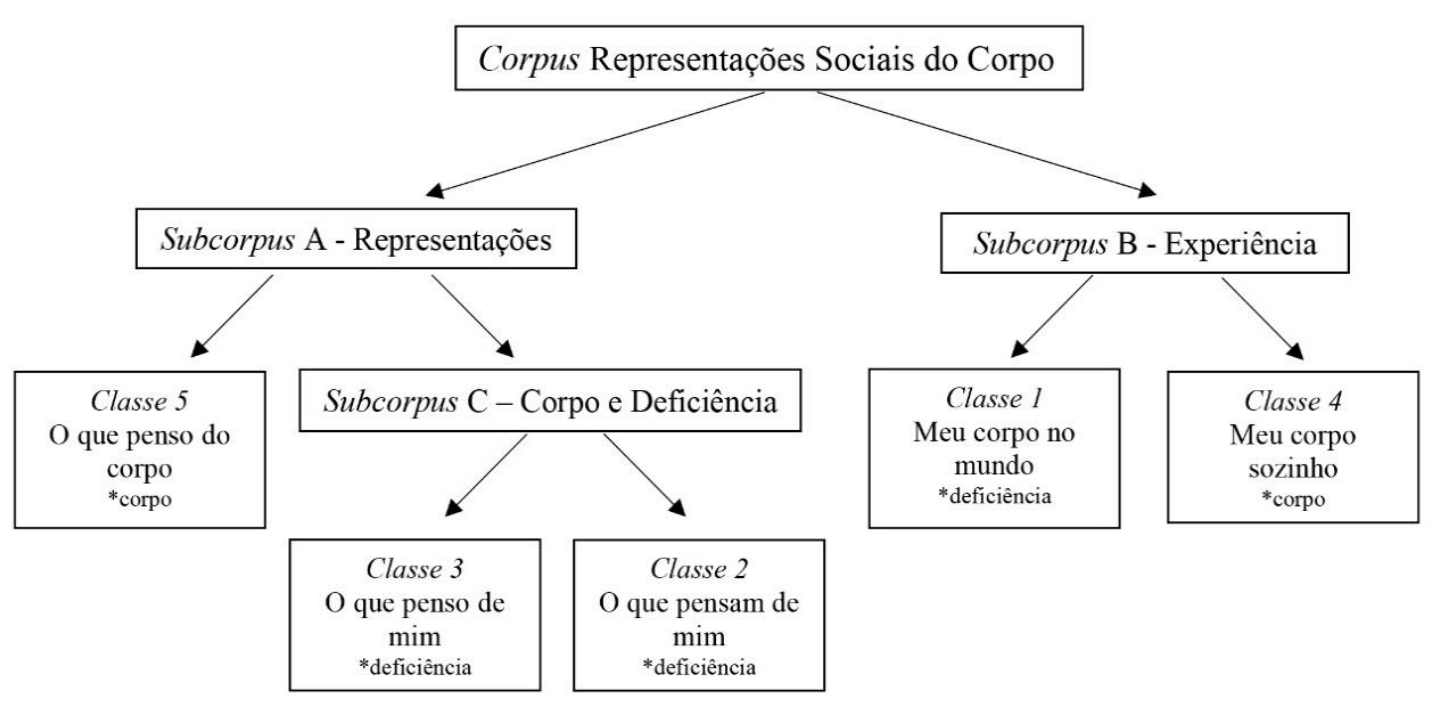

Figura 1. Classes geradas pelo programa IraMuTeQ.

A Figura 2 apresenta as classes juntamente com suas respectivas palavras características, frequência e qui quadrado. Foram listadas as 20 palavras com maior associação à classe, esse ponto de corte teve objetivo de demonstrar os elementos mais representativos de clada classe. A associação foi verificada por meio de teste de qui-quadrado, sendo considerado significativo um valor de $\chi^{2}$ a partir de 3,84, considerando parâmetros de distribuição de qui-quadrado em uma tabela com grau de liberdade igual a 1 e $p$-valor igual a 0,05 .

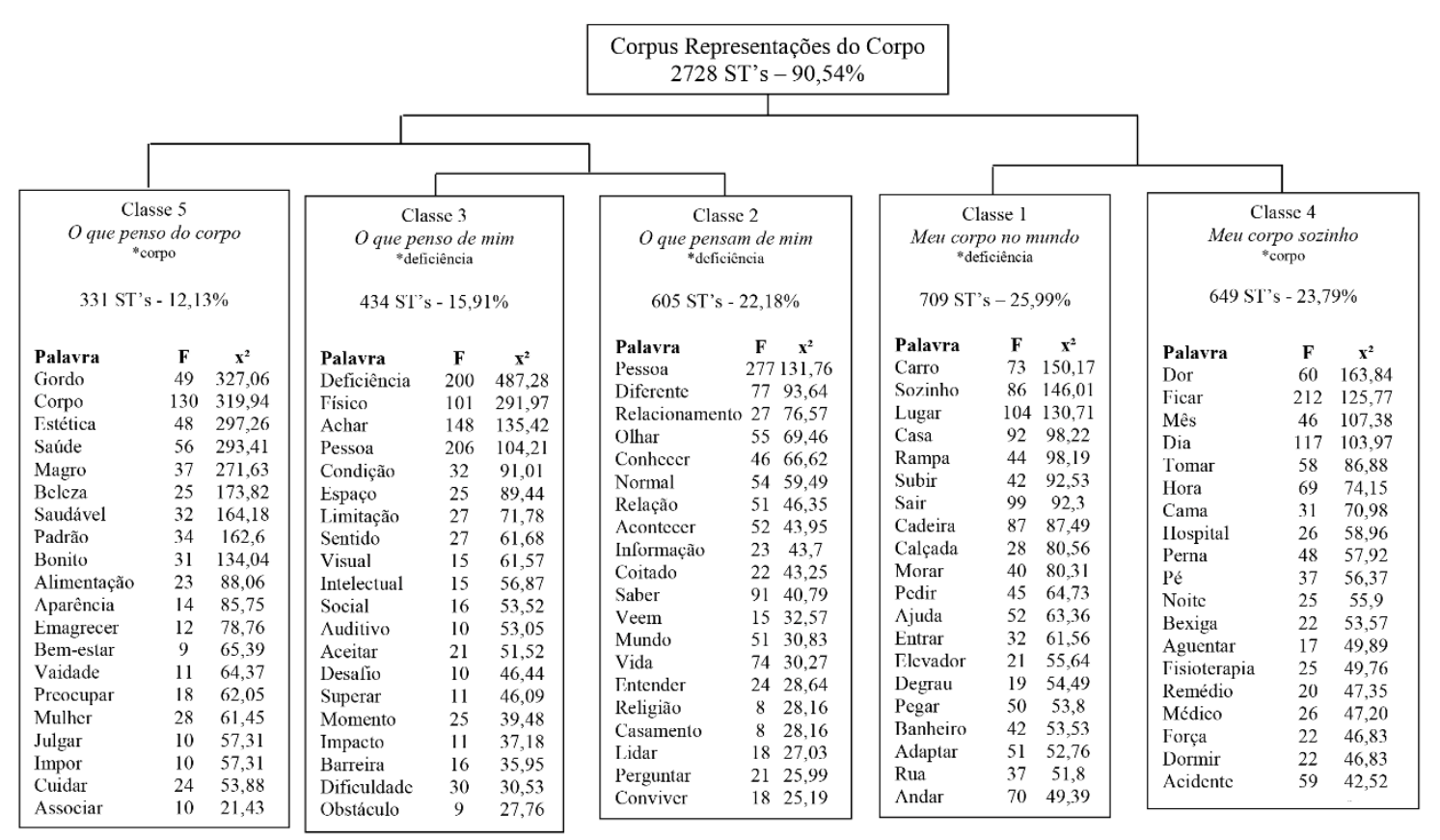

Figura 2. Dendrograma das Representações Sociais do Corpo 
A primeira subdivisão a se separar do restante do corpus, "Experiência", originou as Classes 1 e 4 e traz relatos de vivências dos entrevistados relacionados à lesão e condição de deficiência. A Classe 1 corresponde a 25,99\% dos segmentos de textos e foi intitulada "Meu corpo no mundo"; os segmentos associam-se ao questionamento sobre deficiência. Os relatos evidenciam como a acessibilidade pode facilitar ou dificultar o acesso aos espaços e a uma vida comum. Ter um carro adaptado aparece como elemento para a autonomia e facilitador para o acesso ao trabalho, pois o transporte coletivo não proporciona acesso a todos os lugares:

Eu saio de carro, eu me viro bem de carro, guardo a cadeira, consigo circular bem de carro. Mas eu só vou daqui para o meu trabalho, daqui para o shopping, daqui para o supermercado, não dá para ir em qualquer lugar. (Participante 22, sexo feminino)

A insatisfação com a qualidade das vias aparece como conteúdo comum aos entrevistados, pois mesmo que existam rampas, a maior parte não permite o trânsito seguro com a cadeira de rodas devido a irregularidades. Além disso, relatam as atividades que realizam sozinhos e as que precisam solicitar ajuda. Observa-se a relação entre maior grau de dependência e maior insatisfação com o ato de solicitar ou precisar de ajuda:

Mas não é uma coisa muito fácil, tanto faz qual a deficiência, sempre vai ter alguma coisa dificultando a vida. Às vezes não consegue sair sozinho, não consegue fazer tal coisa sozinho, sempre tem que estar precisando de ajuda. Não é uma coisa muito fácil não, na verdade a gente precisa da vontade dos outros. (Participante 20, sexo feminino)

A Classe 4, nomeada "Meu corpo sozinho", corresponde a 23,79\% dos segmentos de textos. Seus conteúdos são característicos do questionamento sobre corpo, sobretudo, trazem as novas relações corporais após a aquisição da deficiência. Os segmentos trazem a relação com o corpo principalmente nos aspectos de saúde. A dor aparece como fator crucial na vida, sendo constante e limitante. Os segmentos de textos desta classe trazem a rotina destinada à recuperação e internação no ambiente hospitalar, também se referem à reabilitação e processo de adaptação.

A experiência com o corpo pós-lesão também trouxe uma rotina de remédios, visitas a médicos, necessidades de fisioterapias para a manutenção da funcionalidade e bem-estar físico, cuidados corporais prevenindo machucados e escaras. Sobretudo, muitos participantes trouxeram às dificuldades que enfrentam em razão da bexiga neurogênica, e a falta de controle da micção que traz limitações, devido às sondagens necessárias de horas em horas e os espaços públicos que não possuem banheiros acessíveis, gerando situações embaraçosas; como demonstra o trecho a seguir:

Sempre tem um escape de urina e eu tenho que usar fralda, isso não me incomoda também, mas acaba sendo um impedimento. Eu não consigo ir ao banheiro, a bexiga me incomoda, ser deficiente não, a bexiga neurogênica sim. (Participante 18, sexo feminino)

Uma segunda subdivisão, nomeada "Representação", distinguiu a Classe 5 da terceira subdivisão "Corpo e Deficiência". A Classe 5 representa 12,13\% do total e foi intitulada "O que penso do corpo" visto que seu conteúdo traz representações relacionadas a um corpo padrão e sem deficiência. As palavras gordo, corpo, estética, saúde, magro, beleza são as que se associam a classe e os segmentos de texto trazem a imposição de um padrão estético acerca do corpo, uma norma social, sendo a pessoa gorda àquela que mais foge da norma de beleza, e a mulher a mais cobrada:

Mas me parece que o padrão atual é voltado para o magro, malhado, tanto para o homem quanto para a mulher. Se você for magro, mas não malhado e não sarado, ainda passa, mas o 
gordo vira ponto de referência. Quando você vai indicar alguma coisa, é lá perto daquele gordinho lá. (Participante 04, masculino)

Os segmentos da Classe 5 evidenciam que ora os cuidados ao corpo são relativos à saúde ora à estética e em muitas vezes o bonito está associado ao saudável. Contudo, quando ligado à estética se refere ao social, no individual volta-se para saúde. Alguns participantes citaram a necessidade de se manterem magros a fim de facilitar o uso da cadeira de rodas e seu transporte. A manutenção do peso ocorre por meio de atividades físicas e reeducação alimentar. Ainda nesse contexto, foi citada a insatisfação com o peso corporal posto que é algo que pode ser modificado - diferentemente da deficiência. $\mathrm{O}$ trecho a seguir ilustra esse contexto:

Especialmente por causa que pode ter deformidades e uma infinidade de coisas, eu passei a me preocupar com o corpo não por uma questão estética, mas por uma questão de saúde. (Participante 19, sexo feminino)

A terceira subdivisão, nomeada "Corpo e Deficiência" traz às relações do corpo com a condição de pessoa com deficiência e originou as Classes 3 e 2. A Classe 3, intitulada "O que penso de mim" corresponde a 15,91\% dos segmentos de texto. Seus conteúdos evidenciam principalmente as representações da própria condição de pessoa com deficiência física e trazem percepções da deficiência como um todo. Apesar de terem a percepção de que são pessoas normais, expressam as limitações e desafios que enfrentam diante dos obstáculos que encontram socialmente:

Depois segue a vida e se torna natural, normal. Depois se torna igual uma outra pessoa que não tem deficiência, vai se tornando natural. É uma adaptação, você muda o seu modo de pensar. (Participante 01, sexo masculino)

Tem essa normalidade imposta pela medicina que a sociedade diz o que é normal e anormal, mas eu acho que a deficiência física é mais relacionada a questão de acesso, de você não conseguir ir em algum lugar. (Participante 18, sexo feminino)

A Classe 2 corresponde à $22,18 \%$ e foi nomeada "O que pensam de mim", também traz elementos da condição de pessoa com deficiência, mas como são vistos socialmente. Relatam à falta de informação que as pessoas têm sobre a deficiência, criando estereótipos errôneos e reforçando a visão de incapacidade e pena.

As pessoas te olham e perguntam: O que aconteceu? Ai coitada! A sociedade tem muito preconceito. Só porque a pessoa está na cadeira de rodas ou porque não tem uma perna ou um braço, não quer dizer que ela não é capaz. É uma pessoa igual às outras, só com algumas dificuldades, mas igual as outras. A sociedade não vê, muita gente pergunta: ela mora sozinha? Ela faz comida? Como ela consegue fazer sozinha? Como ela consegue limpar a casa? (Participante 24, sexo feminino)

A Classe 2 também evidencia os relacionamentos pessoais após a lesão, sobretudo os relacionamentos amorosos. Os homens relataram que não veem muita diferença na forma como se relacionam amorosamente antes ou depois da lesão, mantiveram seus relacionamentos ou criaram novos e compreendem que as mulheres são mais flexíveis com as variações corporais. Por outro lado, grande parte das mulheres relatou ter dificuldades de criar novos relacionamentos, pois não correspondem aos padrões masculinos de relacionamento e de sexualidade, e não são vistas como passíveis à maternidade. Os trechos a seguir ilustram esse contexto: 
Relacionamento é legal, é bom. Mas é mais comum você ver mulheres sem deficiência com homem com deficiência do que o contrário. Não que eu já não tenha visto, mas é mais comum isso. (Participante 05, sexo masculino)

Acho que muitas vezes os homens julgam as mulheres que tem esse tipo de deficiência como assexuadas, não tem nada a ver, mas tem esse estereotipo. Mas eles não imaginam a pessoa fazendo sexo, então eles já não pensam na possibilidade porque não querem um relacionamento sem sexo, e não conseguem imaginar que é possível. (Participante 22, sexo feminino)

Ao serem questionados sobre o corpo e a deficiência física os participantes trouxeram relatos de suas experiências pessoais. As representações sobre o corpo foram estabelecidas em dois pilares: o corpo sem e o corpo com deficiência e, o último, visto também a partir de dois pontos: de quem tem e não tem uma lesão corporal.

A fim de comparar diretamente as diferenças entre homens e mulheres realizou-se uma análise de especificidades, permitindo verificar diretamente a associação do vocabulário do Corpus com a variável descritora sexo. A Figura 3 demonstra as principais palavras associadas a cada grupo e um respectivo seguimento de texto para contextualizá-las. 


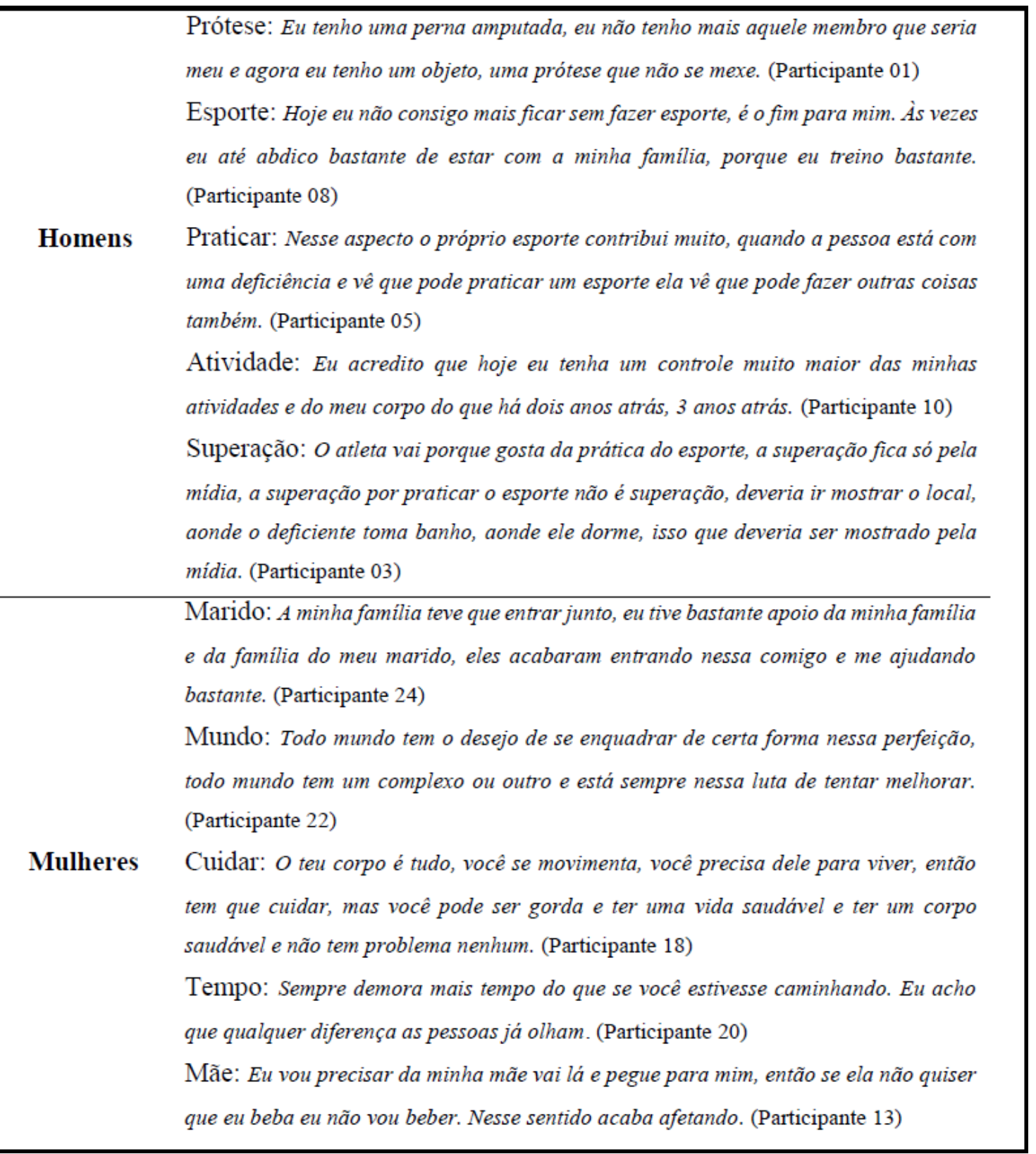

Figura 3. Comparação homens e mulheres na análise de contrastes.

Identificou-se através da análise de contrastes que homens e mulheres possuem particularidades ao relacionar-se com o corpo. Aos homens sobressaíram conteúdos pertencentes à prática de esportes e o aspecto de superação relacionado a esse, atividades físicas e retorno às atividades rotineiras. Os relatos indicam que as atividades físicas proporcionam maior rendimento e qualidade nas atividades cotidianas uma vez que fortalecem a musculatura, além de possibilitar a socialização entre os pares sendo um fator crucial para a informação das (im)possibilidades diante da lesão. Ainda, a palavra prótese associou-se também aos homens, possivelmente pelos entrevistados que sofreram amputações serem do sexo masculino. Nesse sentido, consideram a mesma um instrumento fundamental para a qualidade de vida e facilidade de locomoção.

Nos conteúdos pronunciados pelas mulheres verifica-se que o corpo está vinculado às relações pessoais vividas. $\mathrm{O}$ marido apareceu como agente fundamental para o auxílio de atividades e cuidados com a família. Surgiu a importância de um companheiro que compartilhe o cuidado dos filhos para que se faça possível a maternidade. Ações de cuidado com o corpo, com 
a casa e família foram mencionadas, assim como o cuidado que algumas recebem de suas mães após a lesão, evidenciando a atribuição feminina nessa função. A relação com a falta de tempo para as atividades, como o encontro com amizades ou exercícios físicos, e o maior tempo que levam para concluir tarefas de rotina também foram característicos. Homens e mulheres não apresentaram diferenças significativas nos aspectos de representações sociais enunciados pelas classes do dendrograma, contudo, com a análise de especificidades identificou-se vivências diferentes diante da condição de deficiência, evidenciando a manutenção de comportamentos relacionados aos papéis de gênero.

\section{Discussão}

A análise do corpus permitiu a verificação de duas emblemáticas centrais: as representações do corpo, e aspectos experienciais do corpo com lesão. De acordo com Jodelet (1984) estudos sobre representações sociais do corpo acabam demonstrando dois enfoques: um psicológico, de nível mais individual e subjetivo, que demonstra as relações da pessoa com seu próprio corpo, sensações de prazer ou dor, cotidiano, práticas corpóreas e a sua imagem corporal; e outro coletivo, que se refere à dinâmica do social, incluindo as representações sociais que emergem dos meios de comunicação social, passando pelos papéis sociais e pertencimento a categorias sociais como gênero, classe, deficiência, e que por fim influenciam no conhecimento subjetivo do corpo.

Em referência aos aspectos psicológicos e experienciais do corpo com lesão surgiu a Classe "Meu corpo sozinho" que traz elementos dos primeiros momentos de contato com o corpo, aparecendo a presença da hospitalização, da dor e da relação com os profissionais da saúde. Nesse momento, o corpo como um objeto individual fica em evidência e as concepções do Modelo Médico da Deficiência apresentam-se como centrais. As falas evocadas pelos participantes corroboram o estudo de Moreno-Fergusson e Amaya Rey (2012) onde as mudanças corporais são difíceis de serem enfrentadas pelas pessoas com deficiência física adquirida; mas que com o passar do tempo adquirem conhecimento sobre seu corpo e reconstroem uma nova corporeidade, novas habilidades e visão sobre si mesmo.

Um fato evidenciado por alguns participantes desta pesquisa e visto também por MorenoFergusson e Amaya Rey (2012) é a alteração da percepção do tempo. Muitas vezes a nova forma corporal impede a realização de atividades cotidianas com a mesma agilidade de outras pessoas ou como realizavam antes da lesão.

Percebeu-se que quanto maior o grau da lesão mais os participantes se incomodavam com a dependência e a necessidade de pedir ajuda. Um dos objetivos da reabilitação corporal é justamente que as pessoas com deficiência adquiram maior autonomia em suas atividades diárias. À vista disso, necessita-se falar que o Modelo Social da Deficiência questiona a concepção de deficiência como um aspecto exclusivamente orgânico, mas compreende que a lesão é objeto de cuidados médicos (Mello \& Nuernberg, 2012), cabendo assim a análise sobre as características do ambiente e do arranjo social que criam barreiras para o acesso ao cuidado médico. Nesse sentido, no âmbito do cuidado médico do corpo, um olhar a partir do Modelo Social da Deficiência deve considerar os determinantes sociais da saúde (Nogueira et al., 2016) para que seja possível alcançar promoção da saúde na condição de deficiência.

Ao falarem sobre suas vivências corporais, os participantes com lesões medulares citaram a bexiga neurogênica como um fator crucial e impeditivo de suas rotinas. Encontrado também por Moreno-Fergusson e Amaya Rey (2012) o qual traz que o gerenciamento das funções de excreção ocasiona um impacto direto na vida cotidiana, alterando sua intimidade, privacidade e individualidade. Em estudo de Abbot, Jepson e Hastie (2015) com homens ingleses com Distrofia Muscular de Duchenne as expectativas e normas sociais relacionadas aos papéis de gênero entram 
em conflito direto com o corpo com deficiência e necessidade de cuidados, reduzindo a noção de intimidade e individualidade que para eles seriam condições permitidas às pessoas sem deficiência.

Frequentemente citados nas entrevistas, o ambiente de reabilitação, a relação com os profissionais e a relação com outras pessoas com deficiência emergem como contextos de troca de experiências que potencializam o sentimento de pertença, ajudando na apropriação da condição física (Vasco \& Franco, 2017). Por outro lado, para faz-se necessário ressaltar que no contexto do cuidado, é frequente o estabelecimento de interações sociais em que a pessoa com deficiência recebe tratamento infantilizado, com excesso de proteção, ou ainda com foco na dependência (Carvalho, 2020), dificultando assim o processo de enfrentamento e ressignificação do corpo e da condição física.

Contudo, a reabilitação corporal não traz qualidade de vida isoladamente, outro aspecto evidenciado nas falas relacionadas às vivências corporais dos participantes é de como o ambiente físico que os cercam interage com a nova corporeidade. Essas falas originaram a Classe 1, intitulada "Meu corpo no mundo", uma classe que se articula com as concepções de acessibilidade. A normatização dos espaços para um corpo padrão priva as pessoas com deficiência de seus direitos enquanto cidadãos (Ayres, Nuernberg, \& Rial, 2016). A insatisfação dos participantes sustenta-se em uma questão de direitos humanos; Diniz et al. (2009) relata que a garantia de igualdade entre pessoas sem ou com lesões corporais ultrapassa a oferta de serviços biomédicos, posto que os impedimentos corporais ganham significado a partir das experiências de interação social.

Os conteúdos que trouxeram aspectos de representações sociais nas entrevistas foram divididos em três temáticas: as representações sociais do corpo sem deficiência, representações sociais do corpo com deficiência sob a ótica das próprias pessoas com deficiência física, e por fim, como as pessoas com deficiência física acreditam que as pessoas sem deficiência representem o corpo lesionado. Aspectos das representações sociais do corpo originaram a Classe 5 intitulada "O que penso do corpo" a qual trouxe conteúdos representativos de um corpo padrão e sem deficiência.

Os conteúdos trafegavam ora pela estética e beleza e ora pela saúde e seus cuidados; por vezes associando o bonito ao saudável. O que corrobora com os estudos de Justo, Camargo e Alves (2014) e de Justo e Camargo (2013) em que se evidenciou que o cuidado corporal se relaciona tanto à beleza quanto à saúde. Esses dois objetos se destacam como elementos estruturais nos estudos sobre as representações sociais do corpo, apresentando uma importante zona de intersecção. Nesse sentido, reflete-se sobre a construção das normas sociais e estereótipos ligados à beleza física e ao corpo saudável que se alicerçam sobre a usabilidade do corpo enquanto objeto prático em um ambiente material e social construído para corpos sem deficiência. Tal cenário reforça a relevância e necessidade de que as políticas públicas sejam pensadas a partir do Modelo Social da Deficiência.

Notou-se na fala dos entrevistados que por vezes, quando mencionavam os cuidados pela estética se referiam ao social e a terceiros, já no âmbito individual o discurso é voltado à saúde. Reforçando os achados de Justo et al. (2014) o qual traz que no contexto de saúde a corporalidade é vista como individual. Já no contexto da beleza, a representação está ancorada na relação sujeitomundo o que atribui a essa um peso externo devido às normas sociais. Observa-se, dessa forma, que as representações sociais do corpo para pessoas com deficiência física adquirida se objetifica de modo semelhante aos achados de estudos com pessoas sem deficiência.

Como já mencionado, as representações sociais do corpo estruturaram-se sobre os aspectos de saúde e estética, contudo, particularidades apareceram em outras classes que dizem respeito aos cuidados específicos ao corpo com lesão bem como elementos da funcionalidade e movimento. Wagner (1994) propõe dois níveis na avaliação das representações sociais: o individual e o social. O nível individual refere-se às crenças e percepções de domínio subjetivo e revelam representações sociais de uma determinada categoria social - como apresentou-se na Classe "O que penso de 
mim”. Já o nível social representa as crenças características da cultura e sociedade, representado pela Classe "O que pensam de mim". De acordo com Martins (2015) o corpo social modifica a forma que o corpo físico é percebido, a própria experiência física do corpo é sustentada por uma visão da sociedade.

Observa-se que nas entrevistas a percepção que os participantes tinham de si e de seu corpo correspondiam à normalidade, porém com uma maneira distinta de se atingir a os objetivos de vida, sobretudo, pelas limitações e desafios que enfrentam diante dos obstáculos. As representações do corpo com deficiência ancoraram-se nas representações sociais do corpo, ressalta-se que a palavra "normal" ao fazer referência ao próprio corpo foi enunciada várias vezes. A mudança de hábitos aparece como fator mais impactante do que a mudança corporal. As representações sociais enquanto fenômenos presentes no pensamento social estão em íntima relação com o contexto concreto das práticas, em um processo de mútua influência (Camargo \& Bousfield, 2014) o que demonstra a importância de que sejam garantidas as condições materiais que permitem a participação social e o exercício da autonomia de modo a influenciar os processos dinâmicos de formação do pensamento socialmente compartilhado.

Embora as limitações tenham sido evidenciadas, apareceram também conteúdos positivos relacionados às vivências, com enfoque nas potencialidades e desenvolvimento pessoal. Para muitos, houve uma transformação no significado de viver, à exemplo dos achados de Vasco e Franco (2017) apontando que por mais que a experiência da deficiência seja difícil, não necessariamente se atribui um sentido ruim à vida.

De acordo com Barsaglini e Biato (2015) as mudanças na percepção do corpo lesionado não são lineares, os sentimentos são mobilizados conforme as situações vivenciadas denunciam a diferença, especialmente nas relações heterogêneas com pessoas sem deficiência. A Classe 2 tratase justamente das relações heterogêneas, e, por esse motivo, foi nomeada "O que pensam de mim". Os aspectos representacionais da Classe são voltados ao olhar externo, estigmas e preconceitos; o estereótipo de incapacidade aparece como elemento central.

As representações sociais da deficiência que emergiram dessa classe possuem conotações negativas, pois se referem à doença, fraqueza, incapacidade e pena, dizendo respeito às barreiras atitudinais com que essas pessoas se deparam. Segundo Amaral (2002) as barreiras atitudinais são os preconceitos, estereótipos e estigmas voltados à deficiência que embasam sua segregação social. O estigma do corpo com lesão constitui a condição de pessoa com deficiência (Mello \& Nuernberg, 2012), por mais que se tente descrever situações constrangedoras vivenciadas pelas barreiras atitudinais, Fernandes e Denari (2017) defendem que pessoas sem deficiência jamais saberão o tamanho prejuízo moral que a vivência acarreta.

Morgado et al. (2017) demonstraram uma lacuna nas representações sociais da deficiência entre pessoas com e sem deficiência; as pessoas sem deficiência estavam mais impregnadas de estigmas e apresentaram menos reflexão sobre o assunto. $\mathrm{O}$ discurso emitido aparentava pronto e era pautado nas concepções do modelo médico e patologizante da deficiência. O que vai ao encontro dos dados obtidos no presente estudo, onde se observou que as representações sociais do corpo com deficiência nas relações heterogêneas ancoram-se nas próprias representações sociais da deficiência, que por sua vez, está alicerçada nos modelos biomédicos propagados pelos profissionais de saúde e pelos meios midiáticos. Nesse sentido, a propagação de informações próinclusivas pelos meios midiáticos contribuiria na desconstrução das barreiras atitudinais.

Os estereótipos associados às pessoas com deficiência as consideram não atraentes e assexuadas, afetando os projetos de vida de indivíduos de ambos os gêneros, mas principalmente das mulheres (Gesser et al., 2013). Fato que foi elucidado nesse estudo conforme os conteúdos acerca das experiências amorosas e sexuais após a lesão com parceiros sem deficiência. Homens e mulheres apresentaram diferenças nesse quesito, enquanto os primeiros não verificavam diferenças significativas na forma como se relacionavam amorosamente, as mulheres apresentaram dificuldades em criar novos relacionamentos posto que não correspondem aos 
padrões masculinos buscados em relação à sexualidade. Assim, tendo o corpo como o principal elemento mediador, centralizado na beleza física e saúde, as expectativas e planos de vida em relação à sexualidade são semelhantes entre pessoas com e sem deficiência, todavia, as barreiras para a efetiva vivência da sexualidade é mais significativa quem possui alguma deficiência (Carvalho, 2020).

Corroborando com os achados de Gesser e Nuernberg (2014) os quais mostram que a visão de pessoas com deficiência como assexuadas pode ser atribuída à infantilização dessa categoria social. Segundo os autores, um dos aspectos que dificulta as pessoas com deficiência em relacionar-se sexualmente é o estigma de que pessoas com deficiência são estéreis, gerem filhos com deficiência ou que não possam cuidar deles. Carvalho (2020) refere que o desenvolvimento da sexualidade das pessoas com deficiência se dificulta por conta de barreiras físicas e atitudinais, e que o estereótipo referente à assexualidade das pessoas com deficiência pode ser evidenciado por meio da superproteção familiar, a qual assume uma postura infantilizadora, e com a ausência de educação sexual nos contextos educacionais e sociais.

$\mathrm{O}$ contexto de infantilização é visto principalmente em relação às mulheres, posto que características socialmente ligadas à feminilidade como o ser meiga, frágil, dócil e dependente se potencializam quando deficiência e gênero se interseccionam, sobretudo quando se refere a aspectos da sexualidade, tendo a mídia como reforçador do estigma (Gesser et al., 2013; Luiz \& Nuernberg, 2018). Além disso, a visão de que a mulher com deficiência ocupa uma posição de menor qualificação e de reduzida participação social e política, visão esta já historicamente ligada às relações de gênero desiguais com ou sem deficiência, dificulta ainda mais a aquisição de recursos que contribuam para a autonomia, e desenvolvimento do planejamento de vida como trabalho, cultura, lazer, sexualidade a vivência da maternidade (Nicolau, Schraiber, \& Ayres, 2013).

De acordo com Gesser e Nuernberg (2014), negar a sexualidade da pessoa com deficiência é uma desconsideração à sua condição humana e de direitos, ainda, a falta de informação e despreparo dos profissionais de saúde são fatores que dificultam a prestação de serviços. Para que as pessoas com deficiência sejam de fato sujeitos de direitos é imprescindível que as políticas públicas contemplem o tema da sexualidade; a fim de que sua condição de pessoa comum seja reconhecida bem como seus direitos sexuais e reprodutivos (Mello \& Nuernberg, 2012).

Jones et al. (2015), ao entrevistar mulheres com deficiência física congênita, evidenciou que o corpo com deficiência é considerado um corpo ilegítimo, e que a deslegitimação parece estar mais associado aos aspectos funcionais do corpo do que aos estéticos. Agmon, Sa'ar e AratenBergman (2016) relatam que o corpo com deficiência possui representações que trazem uma posição social reduzida, como representações de dependência, infantilização, assexualidade e estigmas acerca da capacidade cognitiva; o que afetava a autoconfiança dos participantes do estudo mesmo que esses tivessem ciência de que eram subestimados e excluídos. Nesse estudo, evidenciou-se que as representações sociais do corpo para pessoas com deficiência física ilustram os aspectos de saúde e beleza como eixos estruturantes. Ao associá-la com outros elementos representacionais, como a deficiência, o corpo evidencia-se como objeto social posto que o corpo com deficiência se torna um problema quando em interação com um mundo despreparado para lidar com as diferenças. Contudo, percebe-se que a representação da corporalidade com lesões não se distancia completamente das representações sociais do corpo padrão, mas ancora-se nessa concepção.

\section{Considerações finais}

Essa pesquisa teve como objetivo caracterizar as representações sociais do corpo para pessoas com deficiência física adquirida, os resultados demonstram representações sociais do corpo com um enfoque semelhante às encontradas em estudos com pessoas sem deficiência. A 
perspectiva do corpo contorna a saúde e/ou a estética, ao discursarem sobre o corpo com deficiência, mesmo que ainda ancorada nas representações sociais do corpo, os participantes trouxeram novos elementos relacionados ao seu contexto como a rotina de cuidados e funcionalidade corporal, e trouxeram as limitações e obstáculos encontrados. Não foram encontradas diferenças significativas nas representações sociais de homens e mulheres, mas distinguiu-se determinados elementos vivenciais, evidenciando manutenção de comportamento relacionado aos papeis de gênero. Destaca-se que os diversos contextos nos quais os participantes estavam inseridos influi na maneira de ver e vivenciar a sua corporeidade.

Almeja-se que os resultados encontrados colaborem para novos estudos de representações sociais acerca da temática. Tendo em vista as pioras nas condições socioeconômicas brasileiras, o aumento do envelhecimento populacional e das condições crônicas de doença, espera-se um aumento significativo na prevalência de pessoas com deficiência nas próximas décadas. Tornando ainda mais evidente a necessidade de ampliar os estudos de forma interdisciplinar, garantir acesso aos serviços médicos como direito básico e, sobretudo, instituir políticas públicas que contemplem os direitos sociais das pessoas com deficiência. Além disso, os resultados ilustram as diferenças sociais

Visando contribuir para o desenvolvimento de novas pesquisas sobre esse fenômeno são descritas limitações vivenciadas neste estudo: A variável condição socioeconômica não foi controlada. Contudo, notou-se nos conteúdos a diferença quanto à percepção da deficiência de acordo com o nível socioeconômico, uma vez que isso impacta diretamente na relação com o meio social e à condição de igualdade de direitos. Indica-se que novos estudos englobem um número maior de participantes controlando a variável socioeconômica. Ainda, a questão de gênero tem ganhado maior enfoque na sociedade brasileira e representa um núcleo de tensão e discriminação, nesse sentido infere-se que isso afete de forma mais significativa as pessoas com deficiência, devido aos estereótipos e papeis sociais construídos, mostrando-se uma temática relevante para aprofundamento. Em complemento, ressalta-se que o limitado número de estudos sobre representações sociais do corpo no contexto da deficiência dificulta o aprofundamento das discussões dos resultados.

A deficiência apresenta-se como uma condição inerente à vida humana, podendo ser temporária ou permanente, de nascença ou adquirida. Contudo, nota-se a necessidade de mais estudos para que o corpo e a deficiência possam ser compreendidos de forma multidisciplinar; sobretudo, indica-se pesquisas que utilizem da Teoria das Representações Sociais posto que essa contribui diretamente para a compreensão do fenômeno.

Além disso, devido sua presença constante no âmbito individual ou social ressalta-se a importância de inserir a deficiência como uma categoria de análise transversal às pesquisas, como já são estabelecidas categorias como sexo, renda, faixa etária, por exemplo. Por fim, mostra-se pertinente a criação de espaços públicos que se atentem à diversidade corporal e estimulem a participação social das pessoas com deficiência física bem como a criação de políticas públicas de assistência e saúde que considerem suas possibilidades enquanto cidadãos de direitos.

\section{Referencias}

Abbot, D., Jepson, M., \& Hastie, J. (2015). Men living with long-term conditions: exploring gender and improving social care. Health and Social Care in the Community, 24(4), 420-427. doi: $10.1111 / \mathrm{hsc} .12222$

Agmon, M., Sa'ar, A., \& Araten-Bergman, T. (2016). The person in the disabled body: a perspective on culture and personhood from the margins. International Journal for Equity in Health, 15, 147. doi: 10.1186/s12939-016-0437-2

Amaral, L. A. (2002). Diferenças, estigma e preconceito: o desafio da inclusão. Em: M. K. de Oliveira. Psicologia, educação e temáticas da vida contemporânea. São Paulo: Moderna. 
Andrieu, B. (2006). Corps. Em: B. Andrieu (Org.), Le dictionnaire du corps en sciences humaines e sociales (pp. 103-104). Paris: CNRS Editions.

Arruda, A. (2015). Image, social imaginary and social representation. Em: G. Sammut, E. Andreouli, G. Gaskell, \& J. Valsiner. The Cambridge handbook of social representations (pp. 128-142). Cambridge: Cambridge University Press.

Ayres, M. de la B., Nuernberg, A. H., \& Rial, C. S. (2016). Mídia e deficiência: uma abordagem interdisciplinar. R. Inter. Interdisc. INTERthesis, 13(3), 61-80.

Barnes, C., \& Mercer, G. (2001). Disability culture: assimilation or inclusion. Em: G. L. Albrecht, K. D. Seelman, \& M. Bury, Handbook of Disability Studies (pp. 515-534). Oaks: Sage Publications.

Barsaglini, R. A., \& Biato, E. C. L. (2015). Compaixão, piedade e deficiência física: o valor da diferença nas relações heterogêneas. História, Ciências, Saúde-Manguinhos, 22(3), 781796. doi: 10.1590/S0104-59702015000300007

Camargo, B. V., \& Bousfield, A. B. S. (2014). Em direção a um modelo explicativo da relação entre representações sociais e práticas relativas a saúde: a ideia de adesão representacional. Em: E. M. Q. O. Chamon; P. A. Guareschi; P. H. F, Campos. Textos e debates em representações sociais, (pp. 261-284). Porto Alegre: ABRAPSO.

Camargo, B. V., Goetz, E. R., Bousfield, A. B. S., \& Justo, A. M. (2011). Representações sociais do corpo: estética e saúde._Temas em Psicologia (Ribeirão Preto), 19, 257-268.

Camargo, B. V., \& Justo, A. M. (2013). IRAMUTEQ: Um software gratuito para análise de dados textuais. Temas em Psicologia, 21(2), 513-518.

Camargo, B. V., Justo, A. M., \& Aguiar, A. (2008). Corpo real, corpo ideal: a autoimagem definindo práticas corporais. In: Trabalhos Completos do VI Congresso Iberoamericano de Psicologia, Lima, Peru.

Carvalho, A. N. (2020). Representações sociais sobre a sexualidade das pessoas com deficiência: um estudo com universitários com e sem deficiência física. Dissertação de Mestrado. Programa de Pós-Graduação em Psicologia, Universidade Federal de Sergipe, Sergipe. Recuperado de: https://ri.ufs.br/bitstream/riufs/10968/2/ALANA_NAGAI_LINS_CARVALHO.pdf

Castilho, S. M. (2001). A Imagem Corporal. Santo André: Ed. ESETec.

Decreto Legislativo n. 186., de 09 de julho de 2008. (2008). Aprova o texto da Convenção sobre os Direitos das Pessoas com Deficiência e de seu Protocolo Facultativo, assinados em Nova Iorque, em 30 de março de 2007. Brasília, DF: Presidência da República. Acesso em 15 de outubro, 2016, em http://www2.senado.gov.br/bdsf/item/id/99423.

Diniz, D., Barbosa, L., \& Santos, W. R. dos. (2009). Deficiência, direitos humanos e justiça. Sur. Revista Internacional de Direitos Humanos, 6(11), 64-77. doi: 10.1590/S180664452009000200004

Fernandes, A. P. C. dos S., \& Denari, F. E. (2017). Pessoa com deficiência: estigma e identidade. Revista da FAEEBA. Educação e Contemporaneidade, 26(50), 77-89.

Flick, U. (2009). Introdução à pesquisa qualitativa (3a ed.). São Paulo: Artmed.

Furtado, E. R. G. (2009). Representações sociais do corpo, mídia e atitudes. Tese de Doutorado, Universidade Federal de Santa Catarina, Florianópolis, Santa Catarina, Brasil.

Gesser, M., \& Nuernberg, A. H. (2014). Psicologia, Sexualidade e Deficiência: Novas Perspectivas em Direitos Humanos. Psicologia: Ciência e Profissão, 34(4), 850-863. doi: 10.1590/1982370000552013

Gesser, M., Nuernberg, A. H., \& Filgueiras-Toneli, M. J. (2013). Becoming a person in the gender and disability intersection: a research report. Psicologia em Estudo, 18(3), 419-429. doi: 10.1590/S1413-73722013000300004

Ghiglione, R., \& Matalon, B. (1993). O Inquérito - Teoria e Prática. Oeiras: Celta Editora.

Gil, A. C. (2008). Métodos e técnicas de pesquisa social (6ª ed.). São Paulo: Atlas. 
Instituto Brasileiro de Geografia e Estatística. (2011). Censo Demográfico: Resultados Preliminares da Amostra. Acesso em 15 de setembro, 2016, em http://www.ibge.gov.br/home/estatistica/populacao/censo2010/resultados_preliminares_ amostra/default_resultados_preliminares_amostra.shtm

Jodelet, D. (1984). The representation of the body and its transformations. Em: R. Farr \& S. Moscovici (Orgs.), Social representations (pp. 211-238). Cambridge: Cambridge University Press.

Jodelet, D. (1986). La representación social: Fenómenos, concepto y teoría. Em S. Moscovici (Org.), Psicología social (pp. 469-494). Barcelona/Buenos Aires/México: Paidós.

Jodelet, D. (1994). Le corps, la persone et autrui. Em: S. Moscovici (Org.), Psychologie sociale dês relations à autrui (pp. 41-68). Paris: Nathan.

Jodelet, D. (2017). Representações sociais e mundos de vida. Curitiba: PUCPRess.

Jodelet D., Ohana, J., Bessis-Moñino, C., \& Dannenmuller, E. (1982). Systeme de representation du corps et groupes sociaux (relatório vol. 1). Laboratoire de Psychologie Sociale: E.H.E.S.S.

Jones B., S., Duarte B., T., Astorga U., N., Pardo M., M., \& Sepúlveda P., R. (2015). Aproximación a la experiencia de cuerpo y sexualidad de un grupo de mujeres chilenas con discapacidad fisica congenita. Revista Chilena de Terapia Ocupacional, 15(1), 19-32. https://doi.org/10.5354/0719-5346.2015.37127

Justo, A. M., \& Camargo, B. V. (2013). Cuerpo y cognición social. Liberabit: Revista de Psicología, 19(1), 21-32.

Justo, A. M., Camargo, B. V., \& Alves, C. D. B. (2014). Os efeitos de contexto nas representações sociais sobre o corpo. Psicologia: Teoria e Pesquisa, 30(3), 287-297.

Justo, A. M., Camargo, B. V., \& Bousfield, A. B. (2020). Obesidade, representações e categorização social. Barbarói, 56, 164-188. doi: 10.17058/barbaroi.v0i0.14752

Luiz, K. G., \& Nuernberg, A. H. (2018). A sexualidade da pessoa com deficiência nas capas da Revista Sentidos: inclusão ou perpetuação do estigma? Fractal, Rev. Psicol., 30(1),58-65.

Martins, B. S. (2015). Uma reinvenção da deficiência: novas metáforas na natureza dos corpos. Fractal: Revista de Psicologia, 27(3), 264-271. doi: 10.1590/1984-0292/1653

Mello, A. G. de, Nuernberg, A. H., \& Block, P. (2014). Não é o corpo que nos discapacita, mas sim a sociedade: a interdisciplinaridade e o surgimento dos estudos sobre deficiência no Brasil e no mundo. Em: E. Schimanski \& F. G. Cavalcante (Orgs.), Pesquisa e extensão: experiências e perspectivas interdisciplinares (pp. 91-118). Ponta Grossa: Editora UEPG.

Mello, A. G. de, \& Nuernberg, A. H. (2012). Gênero e deficiência: interseções e perspectivas. Revista Estudos Feministas, 20(3), 635-655.

Meurer, B., \& Gesser, M. (2008). O corpo como lócus de poder: articulações sobre gênero e obesidade na contemporaneidade. In Fazendo Gênero 8: Corpo, Violência e Poder, Florianópolis, Santa Catarina, Brasil.

Moreno-Fergusson, M. E., \& Amaya Rey, M. C. del P. (2012). Cuerpo y corporalidad en la paraplejia: significado de los cambios. Avances en Enfermería, 30(1), 82-94.

Morgado, F. F. da R., Castro, M. R. de, Ferreira, M. E. C., Oliveira, A. J. de, Pereira, J. G., \& Santos, J. H. dos. (2017). Representações Sociais sobre a Deficiência: Perspectivas de Alunos de Educação Física Escolar. Revista Brasileira de Educação Especial, 23(2), 245260. doi: 10.1590/s1413-65382317000200007

Moscovici, S. (2012). A psicanálise, sua imagem e seu público. Petrópolis, RJ: Vozes (Original publicado em 1961).

Nicolau, S. M., Schraiber, L. B., \& Ayres, J. R. C. M. (2013). Mulheres com deficiência e sua dupla vulnerabilidade: contribuições para a construção da integralidade em saúde. Ciência \& Saúde Coletiva, 18(3), 863-872. doi: 10.1590/S1413-81232013000300032 
Nogueira, G. C., Schoeller, S. D., Ramos, F. R. S., Padilha, M. I., Brehmer, L. C. F., \& Marques, A. M. F. B. (2016). Perfil das pessoas com deficiência física e políticas públicas: a distância entre intenções e gestos. Ciência e Saúde Coletiva, 21(10), 3131-3142. doi: 10.1590/1413812320152110.17622016

Sampieri, R. H., Collado, C. F., \& Lucio, P. B. (2013). Metodologia de Pesquisa. São Paulo: McGraw Hill.

Vasco, C. C., \& Franco, M. H. P. (2017). Indivíduos Paraplégicos e Significado Construído para o Lesão Medular em suas Vidas. Psicologia: Ciência e Profissão, 37(1), 119-131. doi: 10.1590/1982-3703000072016

Veloz, M. C. T., Nascimento-Schulze, C. M., \& Camargo, B. V. (1999). Representações sociais do envelhecimento. Psicologia Reflexão e Crítica, 12(2), 470-50.

Wagner, W. (1998). Sócio-gênese e características das representações sociais. Em: A. S. P. Moreira \& D. C. de Oliveira. (Orgs.), Estudos interdisciplinares de representação social (pp. 3-25). Goiânia: AB.

Yin, R. (2001). Estudo de caso: planejamento e método. Porto Alegre: Bookman.

Participação dos autores: a) Planejamento e concepção do trabalho; b) Coleta de dados; c) Análise e interpretação de dados; d) Redação do manuscrito; e) Revisão crítica do manuscrito.

B.B. contribuiu em a,b,c,d,e; .A.B.S.B.em a,c,d,e; J.P.S. em c,d,e; A.I.G. em c,d,e.

Editora científica responsável: Dra. Cecilia Cracco 